\title{
Color Stability in Temporization
}

\author{
Navjot S. Mann ${ }^{1}$ Ashu Jhamb ${ }^{1}$ Shikha Bajaj ${ }^{1} \quad$ Rahul Arora $^{1}$ \\ ${ }^{1}$ Department of Conservative Dentistry and Endodontics, \\ National Dental College, Dera Bassi, Punjab, India \\ Address for correspondence Shikha Bajaj, MDS, Department of \\ Conservative Dentistry and Endodontics, National Dental College, \\ Dera Bassi, Punjab 140507, India (e-mail: shikhakansra@gmail.com).
}

\begin{abstract}
Keywords

- color stability

- Protemp

- Revotek

Introduction Provisional restoration refers to a prosthesis which is designed to enhance the esthetic value, or function for a short time, following which it is replaced by using a fixed prosthesis. Color stability is very important factor to be kept in mind during selection of provisional materials in aesthetically important areas. Although there are various studies which look into the issue of stability of color of provisional restorations, the results are contradictory and confusing. This study was planned to compare the color stability of commonly used provisional restorative materials after exposing them to various kinds of discolorants.

Materials and Methods This work evaluated the effect of five common beverages, including tea, on color changes of different provisional materials: 1) Polymethyl methacrylates (DPI); 2) Bisacryl composite (ProtempTM II-3M ESPE); 3) Light polymerized composite (Revotek LC-GC). Color measurement of all specimens was compared with the original values of each specimen prior to immersion.

Results Within the limitations of this study, it was concluded that:

a) There is no difference in color stability of provisional materials.

b) Only food dye produced a clinically appreciable color change, whereas color change by cola and coffee cannot be appreciated by humans and that of tea can be appreciated only by trained eyes.
\end{abstract}

\section{Introduction}

Provisional restoration refers to a prosthesis which is designed to enhance the esthetic value for a short period, following which it is replaced by a fixed prosthesis. Provisional crown and bridge restorations serve many purposes including restoration of function, protection of the teeth and periodontal tissues, stabilization of the occlusion, and diagnostic evaluation prior to the fabrication of the final restoration. ${ }^{1,2}$ Their discoloration may result in dissatisfaction among patients and an extra cost for replacement. ${ }^{3-5}$ Hence, color stability is very important factor to be kept in mind during selection of provisional materials in aesthetically important areas. Several materials with different compositions are available for provisional restoration, but all these materials have shown the property of sorption (absorption and adsorption), due to which they are not color stable for longer duration. Although there are various studies which look into the issue of stability of color of provisional restorations, ${ }^{4,6}$ the results are contradictory and confusing in nature. This study was planned to compare the color stability of the three most commonly used provisional restorative materials in clinical practice after exposing them to various kinds of beverages and food materials.

\section{Materials and Methods}

\section{Provisional Materials}

Manufacturers' instructions were followed to mix the materials under study:

1. Polymethyl methacrylates (DPI);

2. Bisacryl composite (ProtempTM II-3M ESPE);

3. Light polymerized composite (Revotek LC-GC).

After polymerization, gross trimming was conducted. They were subsequently polished using pumice and diamond polishing paste (YETI DENTAL) to make 25 resin discs each. Thus, a total of 75 discs of equal size (thickness $=3 \mathrm{~mm}$, diameter $=20 \mathrm{~mm}$ ) formed the study materials. published online

April 2, 2020
DOI https://doi.org/

10.1055/s-0040-1708076

ISSN 2321-1482. (c) 2020 Bhojia Dental College and
Hospital affiliated to Himachal
Pradesh University

License terms 


\section{Preparation of Staining Solutions}

1. The tea solution was prepared by dipping 1 tea bag (Taj Mahal, Hindustan Unilever Limited, India, 2 g) into $100 \mathrm{~mL}$ of boiling water for 10 minutes.

2. Coffee solution was prepared with commercially available instant coffee powder (Nescafe classic, Nestle India Limited, India) using $15 \mathrm{~g}$ coffee and $100 \mathrm{~mL}$ of distilled water.

3. For cola solution, commercially available brand of cola (Pepsi) was used.

4. A food dye solution was prepared by mixing $500 \mathrm{mg}$ of food dye powder (in $100 \mathrm{~mL}$ of distilled water.

A $1: 2 \mathrm{v} / \mathrm{v}$ mixture of staining solution and artificial saliva was made. The discs of each group were placed in the above-mentioned solutions for 25 days at $37^{\circ} \mathrm{C}$ which was changed every 5 days.

\section{Color Measurements}

CIE (Commission Internationale de l'Eclairage) $l^{*} a^{*} b^{*}$ scale, using reflectance spectrophotometer, was used for color measurements.

Baseline measurements were made after immersing the specimens in distilled water at $37^{\circ} \mathrm{C}$ for a period of 72 hours to eliminate residual monomers. Specimens were randomly divided into five groups $(n=5)$ and their color was measured (three readings per disc). After this, they were dipped at $37^{\circ} \mathrm{C}$ for 25 days in five different solutions and in a manner described earlier. Subsequently, the specimens were washed and color measurements done. The change in color $(\Delta \mathrm{E})$ was calculated.

\section{Results}

Mean values are shown in - Table 1. Acquired data had to be transformed to show a normal and homogeneous distribution. Mean and standard deviation (SD) of this data are shown in - Table 2. Two-way ANOVA and Tukey's tests were used as applicable for statistical evaluation. No statistical significance was seen when various provisional materials $(\mathrm{DPI}=\mathrm{PROTEMP}=\mathrm{REVOTEK}$ ) were compared; however, there existed a statistical difference among solutions $(p<0.05)$. It was found that all solutions, except cola, differed from the control group. They also showed different characteristics when compared with each other. This allowed us to organize the means of transformed data in increasing order (water $=$ cola $<$ coffee $<$ tea $<$ food dye). A graph $(-$ Fig. $\mathbf{1})$ was constructed to view the interaction between solutions and various provisional materials.

Table 1 Mean values of original $\Delta \mathrm{E}$ data

\begin{tabular}{|l|l|l|l|}
\hline Group & DPI & PROTEMP & REVOTEK \\
\hline Water & 0.75 & 0.85 & 0.53 \\
\hline Cola & 0.81 & 0.85 & 0.95 \\
\hline Coffee & 1.07 & 1.19 & 2.24 \\
\hline Tea & 2.35 & 1.94 & 2.47 \\
\hline Food dye & 3.79 & 3.29 & 3.97 \\
\hline
\end{tabular}

\section{Discussion}

An ideal provisional restorative material must fulfill biological, mechanical, morphological, psychological, and esthetic requirements such as good marginal adaptation, retention and resistance to dislodgement during normal masticatory function, strength and durability, and being nonirritating, nonporous and dimensionally stable. It should also be comfortable, highly polished and highly color stable, maintain physiological contours, embrasures and occlusion, and easy to remove and replace by the dentist. ${ }^{7.8}$

Provisional materials can be classified according to the type of resin. ${ }^{9}$ These are as follows:

- Polymethyl methacrylates.

- Bisacryl composites.

- Urethane dimethacrylates.

Polyethyl methacrylates are the oldest of all provisional materials. Bisacryl composites possess the advantages of lower curing temperature, reduced polymerization shrinkage, improved marginal fit, and better color stability. Urethane dimethacrylates have good mechanical properties, some control over its working time, and color is relatively stable but marginal fit can be poor.

In the present study, one material from each group is studied for its color stability in different staining solutions. According to our result, there exists no statistically significant difference in color stability of provisional materials.

Color stability can be evaluated visually and by instrumental techniques using spectrophotometer and colorimeter. ${ }^{10}$ Color perception is a psychophysical phenomenon and includes variation between individuals and within an individual at different times, so to eliminate such an error, instrumental technique is preferred.

Spectrophotometers contain monochromators and photodiodes that measure the reflectance curve of a product's color every $10 \mathrm{~nm}$ or less. ${ }^{11}$ Therefore, spectrophotometers have been shown to be more accurate in measuring the color change than colorimeters, so in the present study, spectrophotometer was used.

Various studies have reported different thresholds of color difference above which the color change is perceptible to the human eye. We have used the National Bureau of Standards (NBS) classification for the same (-Table 4). ${ }^{12,13}$ Data was transformed by the formula NBS unit $=\Delta \mathrm{E} \times 0.92 .12-14$ - Table 3 shows the NBS units obtained this way.

Table 2 Mean values and SD of transformed $\Delta E$ data

\begin{tabular}{|l|l|l|l|l|}
\hline Group & DPI & PROTEMP & REVOTEK & Mean \\
\hline Water & $0.93(0.16)$ & $0.98(0.20)$ & $0.80(0.20)$ & $0.90(0.20)$ \\
\hline Cola & $0.96(0.23)$ & $0.98(0.12)$ & $1.02(0.20)$ & $0.98(0.18)$ \\
\hline Coffee & $1.07(0.16)$ & $1.11(0.09)$ & $1.37(0.23)$ & $1.14(0.18)$ \\
\hline Tea & $1.39(0.10)$ & $1.31(0.12)$ & $1.41(0.12)$ & $1.40(0.12)$ \\
\hline Food dye & $1.59(0.18)$ & $1.53(0.14)$ & $1.61(0.06)$ & $1.60(0.13)$ \\
\hline Mean & $1.19(0.3)$ & $1.18(0.3)$ & $1.24(0.3)$ & \\
\hline
\end{tabular}




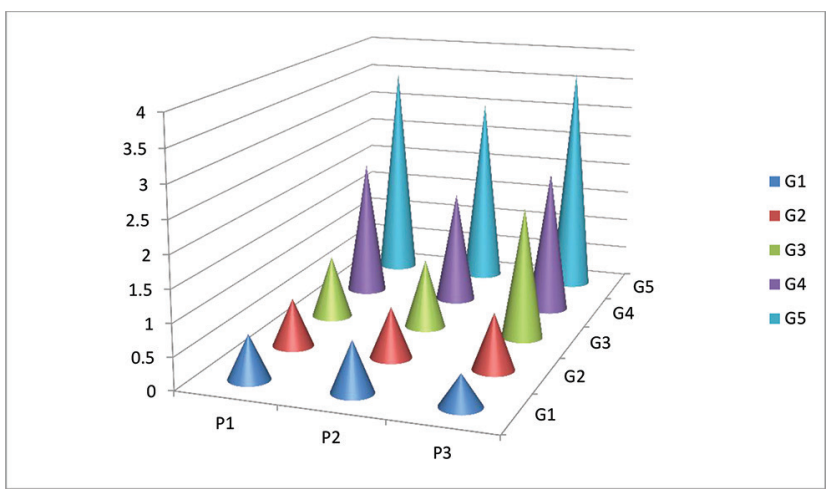

Fig. 1 Mean $\Delta \mathrm{E}$ values according to solution and provisional materials. This figure shows that the color change produced by coffee was much higher in REVOTEK than in DPI and PROTEMP, which may indicate interaction between coffee and the REVOTEK.

Table 3 Means values of NBS units

\begin{tabular}{|l|l|l|l|l|}
\hline Group & DPI & PROTEMP & REVOTEK & Mean \\
\hline Water & 0.69 & 0.79 & 0.49 & 0.66 \\
\hline Cola & 0.75 & 0.79 & 0.88 & 0.81 \\
\hline Coffee & 0.99 & 1.09 & 2.07 & 1.39 \\
\hline Tea & 2.17 & 1.79 & 2.27 & 2.08 \\
\hline Food dye & 3.49 & 3.03 & 3.66 & 3.39 \\
\hline
\end{tabular}

Abbreviation: NBS, National Bureau of Standards.

The observations from this study and previous research ${ }^{15-18}$ show that the types of staining agent or exposure conditions are major factors that affect color stability of provisional restorative materials.

Pigments dissolved in water and other fluids that are consumed by the patients can get absorbed and adsorbed by the restorative materials and cause their color to change. ${ }^{12,19,20}$ This absorption occurs mostly due to the hydrophilic nature of polymethylmethacrylate (PMMA) and the porosity created while mixing. ${ }^{21-23}$ Other possible reasons which can contribute to color instability are roughness of the surface, oxidation, dehydration, water absorption, and product degradation. ${ }^{12,21}$ In our study, all the provisional materials showed the same behavior regarding $\Delta \mathrm{E}$. The results of the Gupta et al. ${ }^{24}$ showed that Revotek LC provisional restorative material was most color stable, followed by Protemp, Systemp and DPI. In a study conducted by Koumjian et al, ${ }^{25}$ an autopolymerizing methylmethacrylate resin (cold pack) was less color stable than bisacryl composite (Protemp), whereas Truekit and Duralay were more color stable. When comparing solutions, similar behavior was observed in cola and distilled water, with both classified as slight change rate according to NBS classification. ${ }^{12,13}$ Similar findings were reported by Guler et $\mathrm{al}^{26}$ Although coffee showed greater $\Delta \mathrm{E}$ than cola and water, its mean value (1.14) as well as its NBS unit (1.39) was within the acceptable limit. ${ }^{27-29}$ However, it may be noted ( - Table 3 ) that REVOTEK, dipped in coffee, had a mean value of 2.07, which is higher than 1.5 (perceivable as per NBS classification). ${ }^{12,13}$
Table 4 NBS rating system for expressing color difference

\begin{tabular}{|l|l|}
\hline NBS Units & Critical remarks on color difference \\
\hline $0.0-0.5$ & Extremely slight change \\
\hline $0.5-1.5$ & Slight change \\
\hline $1.5-3.0$ & Perceivable change \\
\hline $3.0-6.0$ & Marked change \\
\hline $6.0-12.0$ & Extremely marked change \\
\hline$>12.0$ & Change to other color \\
\hline
\end{tabular}

Abbreviation: NBS, National Bureau of Standards.

Tea has a greater concentration of pigments in its solution. Our results are similar to the findings that tea has greater pigmentation potential than coffee $\mathrm{e}^{20,30,31}$ but different from those of Imirzalioglu et al, ${ }^{19}$ who found it to be insignificant. This can be explained by the kind of tea and differences in its processing before consumption. Food dye had the greatest $\Delta \mathrm{E}$ of all the solutions tested, as found in others studies. ${ }^{17,21,30,32}$ Although our results seem to be similar to others, the clinical relevance of the beverages consumed shall vary with the consumption pattern and not only the type of beverages or foods consumed. More studies are needed to clarify this aspect.

\section{Conclusion}

Within the limitations of this study, it can be concluded that:

a) There is no difference in color stability of provisional materials.

b) Only food dye produced a clinically appreciable color change (3.39), whereas color change by soft drink (0.81) and coffee (1.39) turned out to be insignificant and that of tea (2.08) can be appreciated only by trained eyes.

However, it may be noted that consumption habits may ultimately change these findings.

\section{Funding}

None.

\section{Conflict of Interest}

None declared.

\section{References}

1 Burns DR, Beck DA, Nelson SK; Committee on Research in Fixed Prosthodontics of the Academy of Fixed Prosthodontics. A review of selected dental literature on contemporary provisional fixed prosthodontic treatment: report of the Committee on Research in Fixed Prosthodontics of the Academy of Fixed Prosthodontics. J Prosthet Dent 2003;90(5):474-497

2 Doray PG, Eldiwany MS, Powers JM. Effect of resin surface sealers on improvement of stain resistance for a composite provisional material. J Esthet Restor Dent 2003;15(4):244-249

3 Sham AS, Chu FC, Chai J, Chow TW. Color stability of provisional prosthodontic materials. J Prosthet Dent 2004;91(5):447-452

4 Haselton DR, Diaz-Arnold AM, Dawson DV. Color stability of provisional crown and fixed partial denture resins. J Prosthet Dent 2005;93(1):70-75 
5 Ergün G, Mutlu-Sagesen L, Ozkan Y, Demirel E. In vitro color stability of provisional crown and bridge restoration materials. Dent Mater J 2005;24(3):342-350

6 Türker SB, Koçak A, Aktepe E. Effect of five staining solutions on the colour stability of two acrylics and three composite resins based provisional restorations. Eur J Prosthodont Restor Dent 2006;14(3):121-125

7 Anthony HL. Dr Dent, Temperature rise in the pulp chamber during fabrication of provisional crowns. J Prosthet Dent 1989; (62):622-626

8 Federick DR. The provisional fixed partial denture. J Prosthet Dent 1975;34(5):520-526

9 Ulker M, Ulker HE, Zortuk M, Bulbul M, Tuncdemir AR, Bilgin MS. Effects of current provisional restoration materials on the viability of fibroblasts. Eur J Dent 2009;3(2):114-119

10 Okubo SR, Kanawati A, Richards MW, Childress S. Evaluation of visual and instrument shade matching. J Prosthet Dent 1998;80(6):642-648

11 Canay S, Hersek N, Tulunoğlu I, Uzun G. Evaluation of colour and hardness changes of soft lining materials in food colorant solutions. J Oral Rehabil 1999;26(10):821-829

12 Sepúlveda-Navarro WF, Arana-Correa BE, Borges CP, Jorge $\mathrm{JH}$, Urban VM, Campanha NH. Color stability of resins and nylon as denture base material in beverages. J Prosthodont 2011;20(8):632-638

13 Ergun G, Nagas IC. Color stability of silicone or acrylic denture liners: an in vitro investigation. Eur J Dent 2007;1(3):144-151

14 Um CM, Ruyter IE. Staining of resin-based veneering materials with coffee and tea. Quintessence Int 1991;22(5):377-386

15 Crispin BJ, Caputo AA. Color stability of temporary restorative materials. J Prosthet Dent 1979;42(1):27-33

16 Doray PG, Li D, Powers JM. Color stability of provisional restorative materials after accelerated aging. J Prosthodont 2001;10(4):212-216

17 Doray PG, Wang X, Powers JM, Burgess JO. Accelerated aging affects color stability of provisional restorative materials. J Prosthodont 1997;6(3):183-188

18 Yannikakis SA, Zissis AJ, Polyzois GL, Caroni C. Color stability of provisional resin restorative materials. J Prosthet Dent 1998;80(5):533-539

19 Imirzalioglu P, Karacaer O, Yilmaz B. Ozmen Msc I. Color stability of denture acrylic resins and a soft lining material against tea, coffee, and nicotine. J Prosthodont 2010;19(2):118-124
20 Anil N, Hekimoglu C, Sahin S. Color stability of heat-polymerized and autopolymerized soft denture liners. J Prosthet Dent 1999;81(4):481-484

21 Yannikakis S, Zissis A, Polyzois G, Andreopoulos A. Evaluation of porosity in microwave-processed acrylic resin using a photographic method. J Prosthet Dent 2002;87(6):613-619

22 Anusavice KJ, Phillips, RW, Phillips' Science of Dental Materials. 11th ed. St. Louis, Missouri: Saunders; 2003 721-758

23 Compagnoni MA, Barbosa DB, de Souza RF, Pero AC. The effect of polymerization cycles on porosity of microwave-processed denture base resin. J Prosthet Dent 2004;91(3):281-285

24 Gupta G, Gupta T. Evaluation of the effect of various beverages and food material on the color stability of provisional materials - An in vitro study. J Conserv Dent 2011;14(3):287-292

25 Koumjian JH, Firtell DN, Nimmo A. Color stability of provisional materials in vivo. J Prosthet Dent 1991;65(6):740-742

26 Guler AU, Yilmaz F, Kulunk T, Guler E, Kurt S. Effects of different drinks on stainability of resin composite provisional restorative materials. J Prosthet Dent 2005;94(2):118-124

27 Rutkunas V, Sabaliauskas V, Mizutani H. Effects of different food colorants and polishing techniques on color stability of provisional prosthetic materials. Dent Mater J 2010;29(2):167-176

28 Xu BT, Zhang B, Kang Y, Wang YN, Li Q. Applicability of CIELAB/ CIEDE2000 formula in visual color assessments of metal ceramic restorations. J Dent 2012;40(Suppl 1):e3-e9

29 Assunção WG, Barão VA, Pita MS, Goiato MC. Effect of polymerization methods and thermal cycling on color stability of acrylic resin denture teeth. J Prosthet Dent 2009;102(6):385-392

30 Bonatti MR, Cunha TR, Regis RR. Silva-Lovato CH, Paranhos HF, de Souza RF. The effect of polymerization cycles on color stability of microwave-processed denture base resin. J Prosthodont 2009;18(5):432-437

31 Patel SB, Gordan VV, Barrett AA, Shen C. The effect of surface finishing and storage solutions on the color stability of resin-based composites. J Am Dent Assoc 2004;135(5): 587-594

32 Silva PM, Acosta EJ, Jacobina M. Pinto L de R, Porto VC. Effect of repeated immersion solution cycles on the color stability of denture tooth acrylic resins. J Appl Oral Sci 2011;19(6): 623-627 